\title{
Papel do Instrutor de Pediatric Advanced Life Support na Aplicação das Melhores Práticas em Ressuscitação Pediátrica
}

\section{The Role of the Pediatric Advanced Life Support Instructor in Applying Best Practices in Pediatric Resuscitation}

Lisiane Valdez Gaspary ${ }^{I, I}$

Edison Ferreira de Paiva ${ }^{I}$ D

\section{PALAVRAS-CHAVE}

- Treinamento por Simulação.

- Ressuscitação.

- Pediatria.

- Ressuscitação Cardiopulmonar.
${ }^{\mathrm{I} I n s t i t u t o ~ S i ́ r i o-L i b a n e ̂ s ~ d e ~ E n s i n o ~ e ~ P e s q u i s a, ~ S a ̃ o ~ P a u l o, ~ S a ̃ o ~ P a u l o, ~ B r a s i l . ~}$

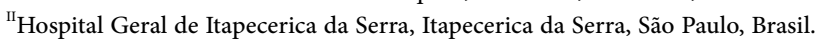




\section{KEYWORDS}

- Simulation Training.

- Resuscitation.

- Pediatrics.

- Cardiopulmonary Resuscitation.

\section{ABSTRACT}

Introduction: Cardiopulmonary arrest is an emergency event that requires both early identification of signs of clinical deterioration and rapid and effective actions for its reversal. Many physicians and nurses who provide care for children seek to training in this area of care by completing the Pediatric Advanced Life Support (PALS) course, and subsequently becoming an instructor. The aim of this research was to understand the PALS instructors' views on their role in connecting simulated scenarios to real life pediatric resuscitation situations. Method: The article has a qualitative approach and semi-structured interviews were used as the research technique. Twelve interviews were conducted with PALS instructors linked to various training centers in São Paulo. For qualitative analysis of the interviews the method proposed by Minayo was used, and Pierre Bourdieu's field and habitus theoretical framework was also adopted. Results: Analysis of the interviews showed that after becoming PALS instructors, physicians and nurses feel recognized and self-confident, are better team leaders, make constructive interventions, suggest more training in pediatric emergencies and implement improvements in their services. The built-in habitus in the simulated field was reproduced by the instructors in the field of assistance, except in the debriefing application. Conclusion: The role of the instructors was to multiply best practices, involving the teams and favoring the execution of systematized and evidence-based care, with positive results in the day-to-day of hospital institutions.

Recebido em 30/1/20

Aceito em 5/10/20

\section{INTRODUÇÃO}

Se não forem tratadas de modo correto, crianças com insuficiência respiratória e choque circulatório poderão desenvolver insuficiência cardiopulmonar e até mesmo parada cardiorrespiratória (PCR) ${ }^{1}$. Uma vez ocorrida a PCR, mesmo com os esforços ideais de ressuscitação, o resultado, geralmente, é ruim. Em ambiente extra-hospitalar, apenas de $4 \%$ a $14 \%$ das crianças que sofrem PCR sobrevivem à alta hospitalar, e de $15 \%$ a $33 \%$ quando a PCR é intra-hospitalar ${ }^{1-3}$. Logo, o profissional de saúde deve usar abordagem sistemática ao cuidar de uma criança gravemente doente ou ferida, facilitando a rápida identificação dos sinais de insuficiência respiratória e choque e adotando medidas para salvá-la ${ }^{1}$.

Para otimizar a probabilidade de que as vítimas de PCR recebam cuidados da mais alta qualidade, baseados nas melhores evidências disponíveis, consensos publicados periodicamente ${ }^{4}$ subsidiam as diretrizes para a estruturação de cursos de treinamento em ressuscitação ${ }^{4-10}$, como o Suporte Avançado de Vida em Pediatria - SAVP (Pediatric Advanced Life Support - PALS), de acordo com os padrões da American Heart Association (AHA) ${ }^{8}$. No decorrer dos anos, o material dos cursos tem sido atualizado com revisões das diretrizes de emergência e inovação nas técnicas de ensino ${ }^{10}$.

O PALS foi introduzido efetivamente no Brasil em $1997^{5}$ com o objetivo de capacitar os profissionais a reconhecer precocemente e atender adequadamente as crianças com iminente risco de morte e/ou $\mathrm{PCR}^{1}$, a partir da padronização do atendimento. Tanto as manobras executadas no Suporte Básico de Vida (SBV) como as do SAVP exigem equipe bem treinada, pois a PCR requer ações rápidas, eficazes e integradas ${ }^{5}$. Além disso, o atendimento ideal de uma emergência pediátrica depende de infraestrutura (equipamentos e medicamentos) padronizada, implantação de protocolos e procedimentos, cultura organizacional para mudanças, além de liderança comprometida e envolvida ${ }^{11}$.

O curso de PALS normalmente é realizado em centros de treinamentos para médicos e enfermeiros, com aulas teóricas e atividades práticas coordenadas e ministradas por instrutores. Aos alunos são oferecidas informações necessárias para o reconhecimento de crianças em risco de
PCR, habilidades cognitivas e psicomotoras necessárias na ressuscitação e estabilização de pacientes ${ }^{12}$. Nesse contexto, o instrutor de PALS tem um papel importante no aprendizado dos alunos, sendo o responsável no curso por apresentar os casos (briefing), conduzir os cenários e coordenar o feedback (debriefing) ${ }^{1,12}$.

Este estudo procurará verificar qual o papel dos instrutores de PALS que trabalham em hospitais no que se refere à multiplicação das diretrizes do PALS e sua influência na aplicação prática das diretrizes, desde a educação dos profissionais de saúde e formação de equipes de emergência até a implantação de melhorias nos processos e nas infraestruturas relacionadas à ressuscitação pediátrica.

O objetivo geral desta pesquisa foi conhecer a percepção do instrutor de PALS sobre seu papel na articulação entre o cenário simulado (curso) e o real (hospitalar) da ressuscitação pediátrica. Os objetivos específicos foram, também sob a óptica dos instrutores, descrever como eles percebem sua participação na aplicação das melhores práticas de ressuscitação pediátrica, dentro dos serviços assistenciais em que atuam; reconhecer os principais desafios para a implementação dessas melhores práticas; e identificar os resultados sentidos pelo instrutor na assistência, após a implantação dessas melhorias.

\section{MÉTODO}

Delineamento do estudo

Este é um estudo de abordagem qualitativa, cuja técnica de pesquisa foi a entrevista semiestruturada ${ }^{13-15}$, norteada por um instrumento criado e aplicado pelos autores do trabalho.

O critério de inclusão para participar do estudo foi que o profissional instrutor do PALS tivesse experiência prática real em ressuscitação pediátrica, por atendimento hospitalar ou pré-hospitalar. $\mathrm{O}$ critério de exclusão era não ter essa experiência. A constituição da amostra não objetivou a busca de uma representatividade numérica, e sim um "aprofundamento temático"13.

Inicialmente, foi elaborada uma lista com os nomes dos instrutores de PALS de São Paulo vinculados aos variados centros de treinamento, como

REVISTA BRASILEIRA DE EDUCAÇÃO MÉDICA

2 44 (4) : e171; 2020 
o Instituto Sírio-Libanês de Ensino e Pesquisa (IEP/HSL), a Sociedade Brasileira de Cardiologia (SBC), a Sociedade de Cardiologia do Estado de São Paulo (Socesp) e o Instituto do Coração (InCor).

Um filtro aleatório foi feito visando selecionar profissionais médicos e enfermeiros de todos os centros de treinamento da lista. Um e-mail foi encaminhado explicando o objetivo do estudo e questionando se aceitavam participar. Para os que concordaram, agendaram-se o melhor dia e o melhor horário para a entrevista, presencialmente ou via FaceTime. As entrevistas foram gravadas e duraram em torno de 30 minutos.

Entrevistaram-se 12 instrutores do curso de PALS, após verificação de saturação nas respostas, com amostra homogênea das duas categorias profissionais. Realizaram-se as entrevistas entre novembro de 2017 e fevereiro de 2018. Não foi necessário excluir entrevistas, pois todos os instrutores tinham experiência prática.

O bloco I do roteiro foi composto de perguntas que visavam caracterizar o perfil sociodemográfico dos instrutores do PALS. As variáveis foram: sexo, idade, graduação, tempo de formação, pósgraduação, foco da pós-graduação, experiência prévia, principal área de atuação, experiência em gestão na área de saúde, tipo de hospital(is) que trabalha(ou), certificação/acreditação de qualidade do(s) hospital(is), ano de conclusão do curso de instrutor e número de cursos como instrutor durante $o$ ano.

O bloco II foi formado por pergunta aberta ("Eu gostaria que você me contasse sobre sua experiência como instrutor do curso do PALS e se essa experiência teve alguma influência no seu dia a dia no hospital"), dando ao entrevistado a possibilidade de falar livremente sobre o tema proposto.

\section{Análise dos dados}

Os dados qualitativos seguiram o método de análise proposto por Minayo, Cruz Neto et al. ${ }^{15}$, composto pelas etapas básicas de préanálise, análise, tratamento dos dados e interpretação. Manteve-se o sigilo da identidade dos profissionais, sendo as falas codificadas para cada instrutor. Do instrutor 1 ao 6, temos os enfermeiros (E1-E6), e do 7 ao 12, os médicos (M7-M12).

$\mathrm{Na}$ etapa de pré-análise, ocorreu a transcrição dos materiais que foram anotados e gravados. O conteúdo foi organizado e identificado por instrutor, e fez-se uma leitura inicial para separação por classificação temática.

Após, ocorreu a análise dos achados de forma a responder aos objetivos da pesquisa, captando as ideias centrais dos conteúdos. Em seguida, passou-se à compreensão das falas, com o tratamento e a descrição estruturada dos conteúdos, ordenando e categorizando os núcleos de sentido. Para isso, o presente estudo teve como marco teórico os conceitos presentes nas obras do filósofo e sociólogo francês Pierre Bourdieu: o campo ${ }^{16-19}$ e o habitus ${ }^{20-24}$.

\section{Considerações éticas}

Durante as entrevistas, coletou-se o Termo de Consentimento Livre e Esclarecido. Este estudo foi aprovado pelos Comitês de Ética do Serviço Social da Construção Civil do Estado de São Paulo - Seconci SP - e do Instituto Sírio-Libanês de Ensino e Pesquisa, e está cadastrado na Plataforma Brasil com o Certificado de Apresentação para Apreciação Ética (CAAE) no 79621917.9.0000.0083 e 79621917.9.3001.5461.

\section{RESULTADOS E DISCUSSÃO}

A primeira parte do estudo objetivou verificar o perfil sociodemográfico dos sujeitos em seu conjunto, na tentativa de identificar diferenças de percepções entre os grupos de instrutores.

As características dos instrutores levantadas no primeiro bloco (Tabela 1) são de que não houve predomínio de gênero ou de curso de graduação, a idade média foi de 41,1 anos e, em quase $60 \%$, o tempo de formação foi inferior a 20 anos. Em geral, o curso de pós-graduação foi

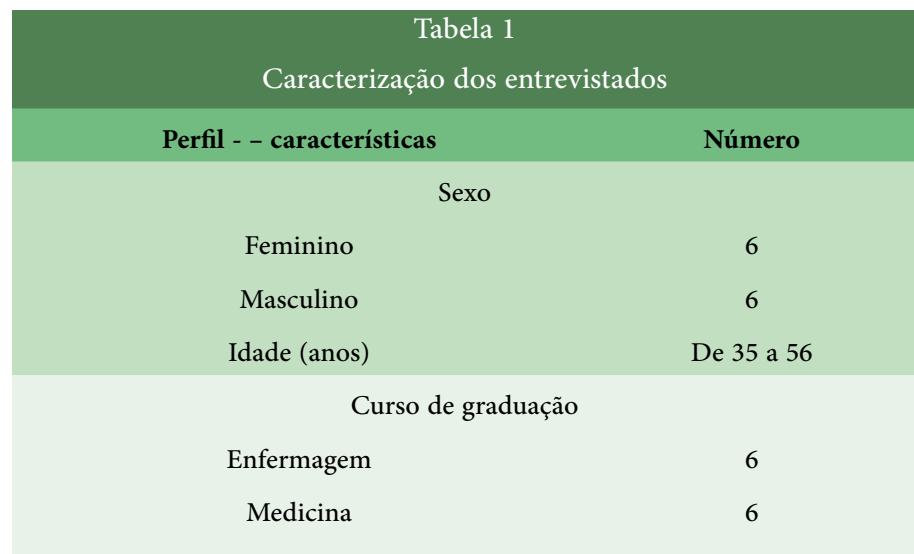

Tempo de formação (anos)

De 11 a 32

\begin{tabular}{|c|c|}
\hline \multicolumn{2}{|c|}{ Pós-graduação ${ }^{(*)}$} \\
\hline Especialização & 7 \\
\hline Residência & 8 \\
\hline Mestrado & 3 \\
\hline \multicolumn{2}{|c|}{ Foco da pós-graduação ${ }^{(*)}$} \\
\hline Pediatria & 5 \\
\hline Terapia intensiva & 7 \\
\hline Cardiologia & 4 \\
\hline Pré-hospitalar & 1 \\
\hline Urgência e emergência & 1 \\
\hline \multicolumn{2}{|c|}{ Experiência prévia ${ }^{(*)}$} \\
\hline Unidade de terapia intensiva pediátrica & 10 \\
\hline Emergência pediátrica & 10 \\
\hline Enfermaria pediátrica & 3 \\
\hline Pré-hospitalar & 2 \\
\hline Outro & 4 \\
\hline \multicolumn{2}{|c|}{ Experiência em gestão na área de saúde } \\
\hline Nenhuma & 5 \\
\hline Gestor de unidade & 6 \\
\hline Diretor & 1 \\
\hline \multicolumn{2}{|c|}{ Em que tipo de hospital(is) você trabalha(ou) $?^{(*)}$} \\
\hline Privado & 10 \\
\hline Público administração direta & 3 \\
\hline Público administração indireta & 2 \\
\hline Filantrópico & 3 \\
\hline Hospital-escola & 9 \\
\hline
\end{tabular}

Continuação..

\footnotetext{
$3 \mid$\begin{tabular}{l|l} 
REVISTA BRASILEIRA DE EDUCAÇÃO MÉDICA \\
\hline $44(4):$ e $171 ; 2020$
\end{tabular}
} 


\begin{tabular}{|c|c|}
\hline \multicolumn{2}{|l|}{$\begin{array}{c}\text { Tabela } 1 \\
\text { Continuação }\end{array}$} \\
\hline Perfil - - características & Número \\
\hline \multicolumn{2}{|c|}{$\begin{array}{l}\mathrm{O}(\mathrm{s}) \text { hospital(is) possui(possuíam) algum tipo de certificação/ acreditação de } \\
\text { qualidade? Qual? }\end{array}$} \\
\hline Joint Commission International (JCI) & 9 \\
\hline Accreditation Canada & 2 \\
\hline Organização Nacional de Acreditação (ONA) & 5 \\
\hline $\begin{array}{l}\text { International Organization for Standardization } \\
\qquad \text { (ISO) }\end{array}$ & 1 \\
\hline Nenhuma & 1 \\
\hline \multicolumn{2}{|c|}{ Quanto tempo é instrutor do PALS? (anos) } \\
\hline Menos 1 ano & 0 \\
\hline $1-5$ & 6 \\
\hline $6-10$ & 2 \\
\hline $11-15$ & 0 \\
\hline Mais de 15 & 4 \\
\hline \multicolumn{2}{|c|}{ Quantos cursos ministra por ano? } \\
\hline $0-15$ & 7 \\
\hline Mais de 15 & 5 \\
\hline
\end{tabular}

$\left.{ }^{\star}\right)$ Itens que podem apresentar mais de uma resposta.

Fonte: Elaborada pelos autores.

a residência, com foco em pediatria ou terapia intensiva, e experiência prévia em unidade de terapia intensiva pediátrica e emergência pediátrica. A maioria $(58,3 \%)$ atua ou atuou em gestão, no setor privado e em hospitais com alguma acreditação de qualidade nacional ou internacional. Em relação ao curso de PALS, 66,7\% têm menos de 15 anos de experiência como instrutor, e 58,3\% ministram até 15 cursos por ano, e três instrutores ministram mais de 40 cursos.

O estudo também procurou organizar os núcleos de sentido das falas, agrupando-os em: condução do atendimento; segurança, reconhecimento e referência; implantações de melhorias; desafios para a implementação das melhores práticas; impacto das mudanças; rotina não incorporada; $\mathrm{e}$ o paciente pediátrico no centro do cuidado.

\section{Condução do atendimento}

Segundo Bourdieu, o campo é um conjunto definido de relações sociais com suas próprias normas e regras de prática, em que as pessoas agem e se comportam $^{16}$. É um ambiente de distintas e desiguais formas de poder e de lutas, construído pela ação de agentes que se enfrentam com meios e fins diferenciados, segundo posições relativas nos espaços de relações.

No curso de PALS, existem as posições de instrutor e aluno, e um possui poder maior que o outro, até como consequência do próprio papel de instrutoria, mas, apesar disso, não há disputa por espaço ou posição. Há uma hierarquia natural imposta pelo método de ensino. Nesse campo, os médicos e enfermeiros são treinados para as mesmas funções e papéis, independentemente da formação.

Numa situação real de emergência, contudo, os enfermeiros não podem executar os papéis para o qual foram treinados, já que, de acordo com as legislações vigentes (Resolução do Conselho Federal de Enfermagem (Cofen) $\mathrm{n}^{\circ} 311 / 2007^{25}$ e as resoluções do Conselho Federal de Medicina $(\mathrm{CFM}) \mathrm{n}^{\text {os }} \cdot 1.931 / 2009^{26}$ e $2.110 / 2014^{27}$ ), somente a equipe médica é responsável por conduzir as equipes multiprofissionais, desfibrilar e prescrever medicamentos. Consequentemente, os enfermeiros têm pouca autonomia para ditar condutas e realizar intervenções, assumindo posição diferenciada e limitada, quando se comparam os dois ambientes de estudo.

Entretanto, os enfermeiros adotam um papel decisivo nessas situações, antecipando-se às condutas médicas e sendo uma barreira em possíveis tratamentos inadequados:

[...] eu nunca assumi uma posição de confronto, tentava ir por um caminho conciliatório: Ah, Dr.! O que você acha de fazer $\operatorname{assim}(E 1)$.

[...] eu faço a intervenção, eu converso em relação à conduta, mas sempre dando a ele a possibilidade de decisão, a conduta é dele (E3).

[...] eu me sinto tão responsável quanto ele; quando você não consegue acessar com diversas técnicas de comunicação, você consegue normalmente um outro profissional médico para se comunicar lá com este profissional (E4).

[...] fazia a intervenção; se ele não mudava, eu falava com o chefe de plantão. Eu não deixo ele fazer. O paciente não é só dele, é nosso, da equipe. Eu dou um jeito. Eu já inventei protocolos institucionais (E5).

Nesses relatos, evidencia-se que os enfermeiros se utilizam do poder adquirido como instrutores (conhecimento) para realizar intervenções construtivas, ou seja, mediando possíveis conflitos, principalmente de condutas divergentes das preconizadas pelo PALS. A experiência teórica e prática dos enfermeiros instrutores permitiu uma abordagem positiva com os médicos. Contudo, nem sempre isso foi possível, sendo por vezes necessária a criação fictícia de protocolos ou a solicitação da presença do chefe de plantão, para que a sugestão fosse aceita pelo profissional que conduzia a emergência.

Já quando o instrutor era médico, ele acabava assumindo o comando da PCR ou norteando a conduta do outro médico:

[...] a ideia é corrigindo na hora, não está bem aqui, faltou alguma coisa, faz (M8).

[...] é difícil, não dá para chegar chutando o pau da barraca e falar você está fazendo tudo errado! Eu assumo com o maior prazer (M12).

\section{Segurança, reconhecimento e referência}

O sentimento de segurança, reconhecimento e referência das equipes também foi o mais citado pelos enfermeiros:
[...] a equipe passou a me ter como referência (E1).
[...] o PALS te dá segurança para fazer a diferença no atendimento (E5).
[...] a gente acaba sendo uma referência, você fala que é instrutor, 
você tem um reconhecimento muito maior (E6).

[...] a gente já sabe qual é a sequência, isto dá muita segurança em termos de não ficarmos com medo (M7).

Ser instrutor do PALS auxiliou esses profissionais a desenvolver habilidades práticas a partir de conhecimentos prévios que os diferenciavam em relação ao restante da equipe assistencial, permitindo a esses médicos e enfermeiros a realização de procedimentos e condutas de forma mais segura e organizada, visando a ações rápidas, eficazes e integradas, o que os tornou reconhecidos e referência para as equipes em que trabalhavam. Essa aprovação fortaleceu a comunicação, a confiança e $\mathrm{o}$ atendimento como um todo.

\section{Implantações de melhorias}

Todos os instrutores conseguiram sugerir e implantar melhorias nos seus serviços, com a intenção de mudar a realidade em que trabalhavam, reproduzindo nas unidades hospitalares o ambiente favorável do atendimento de uma emergência pediátrica vivenciado no curso.

Segundo Zimermmann ${ }^{28}$, mudança organizacional é qualquer transformação de uma natureza estrutural, estratégica, cultural, tecnológica, humana ou de qualquer outro componente, capaz de gerar impacto em parte ou no conjunto da organização. Assim, pode-se verificar que a mudança se relaciona com numerosos fatores, constituindo desafios que podem variar entre demasiadamente simples ou extremamente complexos ${ }^{28}$.

Entre as melhorias sugeridas e incorporadas pelos instrutores, destacam-se:

$$
\text { [...] a prática de exame físico seguindo o } A B C D E \text { (E1). }
$$

[...] aquisição de manequins de bebê, criança e adulto (E2).

[...] implantação de protocolos de emergência e melhorias na área fisica, como compra de monitores melhores e capnógrafos (E3).

[...] padronização do carrinho (E4).

[...] compra de berços aquecidos, estufas de soro (E5).

[...] simulação in situ (E6).

[...] padronização de intraóssea, compra de máscaras de todos os tamanhos para fazer a ventilação não invasiva (M7).

[...] maleta de via aérea dificil e melhorias no carrinho de parada (M8).

[...] mudou a parte de organizar as equipes de enfermagem para ela rodar (M9).

[...] implementou a reanimação in situ, código azul, código amarelo e a de alta fidelidade (M10).

\section{[...] bundle e plano terapêutico (M11).}

[...] revisão de protocolos e implantação de sugestão de folha de doses de parada para criança (M12).

O que se percebeu nas entrevistas é que ser instrutor do PALS refletiu na apropriação do conhecimento, determinação de comportamentos, escolhas e ações práticas, o que fez com que os profissionais agissem de forma coerente com as disposições incorporadas (habitus). Assim, tanto médicos quanto enfermeiros se utilizaram do conhecimento adquirido no campo simulado para modificar o sistema de saúde, os seus locais de trabalho.

Conforme proposto por Bourdieu, a maior parte das ações dos agentes é produto do encontro entre um campo ${ }^{16-19}$ e um habitus ${ }^{20-24}$. Habitus é a identidade social resultante de uma experiência biográfica ${ }^{20}$ coletada, como a tradição, atitudes, opiniões, habilidades e valores ${ }^{21}$, e da interação entre essas experiências ${ }^{22}$. Ou seja, o habitus opera na incorporação de disposições que levam o indivíduo a agir de forma harmoniosa com o histórico de sua classe ou grupo social, e essas disposições incorporadas se refletem nas práticas do sujeito ${ }^{23}$.

Outra constatação é que a maioria dos hospitais era particular, com acreditação de qualidade, o que pode ter influenciado, por pressões externas, o comportamento dos instrutores, o estímulo à implantação de melhorias. Segundo Bourdieu, a mudança institucional não é simplesmente a acumulação individual, mas o desenvolvimento de novos padrões sociais na interação entre habitus e campos que dão origem a oportunidades para a ação transformadora.

O manual de padrões de acreditação da Joint Commission International $(\mathrm{JCI})^{11}$ reforça que o hospital deve utilizar apenas diretrizes de práticas clínicas que foram revisadas e endossadas por fontes competentes relevantes, para padronização do processo de cuidados clínicos, como no caso dos serviços de ressuscitação, que devem realizar intervenções críticas com a disponibilidade rápida de equipamentos médicos padronizados, medicamentos para ressuscitação e profissionais adequadamente treinados. Ou seja, tudo que, de alguma forma, os instrutores tentaram implantar em seus serviços.

\section{Desafios para a implementação das melhores práticas}

Todos os instrutores relataram desafios para a implementação de melhores práticas, como falta de recursos, de treinamento e de apoio da gestão, e até resistência da equipe, sendo essa fala mais perceptível nos profissionais que trabalhavam nos hospitais públicos. Já a falta de apoio dos gestores locais chamou a atenção tanto nas instituições particulares quanto nas públicas, assim como a resistência da equipe.

[...] principalmente financeiro, cai sempre aí, é SUS e prefeitura (E2).

[...] não adianta ter um dispositivo de punção intraóssea, e a equipe não saber utilizar o dispositivo. Dificuldade financeira, as prefeituras não têm dinheiro (E3).

[...] depende um pouco da gestão do local, muda o gestor e isto faz diferença (E5).

[...] às vezes a gente tem um pouquinho de resistência, principalmente alguns médicos que às vezes têm uma maneira de atender diferente (E6).

[...] quando assumi coloquei mais alguns protocolos, mas na prática ninguém seguia, cada um fazia o que dava na cabeça; a gente tentava, mas não era tão fácil (M7).

[...] a gerência não se preocupa; o problema se chama espera política, o superior não acha devidamente necessário (M9). 
[...] lidar com gerações mais velhas, você orientar é bastante difícil, então, os vícios, a falta de reciclagem acaba consolidando vícios (M10).

[...] o que fez com que as pessoas fizessem o PALS foi a exigência da JCI; se não fosse uma exigência da JCI, eu duvido um pouco que haveria todo esse investimento no PALS (M12).

Os desafios citados interferem negativamente nas mudanças organizacionais, como a acomodação e a consequente resistência à mudança que, depois de superadas, podem ser importantes na criação de estabilidade institucional $^{28}$.

Outra observação é que muitos instrutores, conforme Tabela 1, trabalham em hospitais-escola, nos quais historicamente há uma relação hierárquica de professor-aluno que envolve respeito e subordinação às orientações, o que poderia ser um desafio para a mudança organizacional. Contudo, esse espaço social foi apresentado em apenas uma narrativa, demonstrando que, para os instrutores, trabalhar nesse tipo de hospital não influenciou na conduta tomada por eles ante uma emergência pediátrica.

[...] por termos esta formação universitária, nós temos uma hierarquia educacional, se assim pudermos chamar; então nós tentamos respeitar a hierarquia educacional e entender o motivo de cada um ter agido daquela maneira; todos foram meus professores, então eles sabem (M11).

Verificou-se que, apesar de todas as dificuldades para a implementação de mudanças, os instrutores conseguiram com os recursos disponíveis atender às emergências, não necessariamente da forma desejada, mas dentro do possível nas condições existentes. Muitas vezes, não era o antibiótico ou medicamento para inalação mais recomendado, não era uma equipe completa e preparada, mas os instrutores conseguiram enxergar o potencial e extrair o máximo de cada um para o melhor atendimento.

\section{Impacto das mudanças}

A maioria dos instrutores, apesar dos desafios, teve a percepção de mudança nos resultados do atendimento após a implantação das melhorias, o que se evidencia nas seguintes afirmações:

[...] houve melhora gigantesca (E1).

[...] hoje a mortalidade infantil é baixa, praticamente não tivemos óbito infantil (E3).

[...] quando a gente faz tudo direitinho, a gente acaba tendo um melhor resultado (E6).

[...] melhorou muito, a nossa taxa de mortalidade caiu para um terço do que tínhamos antes (M9).

Consequentemente, os resultados na assistência, segundo a óptica dos instrutores, são visíveis e até quantificáveis, e as mudanças resultaram em melhoria, como a redução da mortalidade infantil e a melhor organização das equipes.

Rotina não incorporada: debriefing

Um subtema importante que emergiu nas entrevistas foi a rotina de realização do debriefing, uma discussão de avaliação do tratamento, realizada pelos profissionais participantes ao final do evento. Apenas dois instrutores o referiram como um procedimento sistemático nos serviços, apesar de, no ambiente simulado, ocorrer em todas as finalizações de cenário, o que sugere um comportamento que, infelizmente, apesar de ser uma etapa importante para a reflexão e incorporação de melhorias no processo de PCR, não foi introjetado ainda pelas equipes.

[...] sim, acontece, mas demora um tempo, ter esta capacidade de se autoavaliar não é uma coisa inata do ser humano (E4).

[...] a gente acaba fazendo, mas isto acontece mais entre os profissionais mais envolvidos (E6).

[...] Normalmente a gente faz o debriefing, atualmente, não é uma coisa antiga, é há pouco tempo, fazer discussão de casos com os enfermeiros e também com as técnicas para avaliar o atendimento (M12).

Os instrutores ainda não se sentem à vontade para discutir as oportunidades de melhoria de todos os envolvidos na emergência, como se a discussão ainda estivesse centrada em um profissional, se este errou ou não, e não em falhas da equipe. Ou seja, verifica-se que ainda é necessário um amadurecimento dos hospitais nas discussões para aprendizado e melhorias de processo. Considera-se que essa é uma melhoria que ainda deve ser introjetada à prática dos profissionais da saúde para revisão dos processos e o alcance de um atendimento pediátrico de excelência.

O paciente pediátrico no centro do cuidado

O olhar para o paciente pediátrico foi evidenciado na preocupação em acolher a família durante a ressuscitação, com envolvimento dela respeito, comunicação clara e transparência.

[...] reanimar hoje é mais claro, hoje temos na UTI paliativos, a família já está ciente. Já temos a conduta de deixar a família junto, próximo (E1).

[...] uma parada com criança tem uma carga afetiva, emocional muito diferente de uma parada do adulto, não estou falando de questão de melhor ou pior, estou falando de questão de complexidade. Porque naturalmente não se espera ver uma criança morrer, não faz parte do ciclo da vida (E4).

[...] quando você tem o familiar, o óbito inesperado, realmente a emoção acaba pegando a equipe e acho que isso acaba dividindo a atenção da equipe (M10).

[...] o que às vezes a gente tem é óbito, a gente começa a reanimar por solicitação da família e do médico da criança, mas a gente já sabe de antemão que aquilo não é parada, é óbito, a criança está morrendo (M12).

O que se percebeu é que os comportamentos entre profissionais e paciente/família foram alterados com a convivência e proximidade entre eles, logo, durante uma situação de RCP, investe-se mais no atendimento de uma criança, afinal, não se espera que um paciente morra tão cedo, assim como, algumas vezes, essa reanimação só é realizada por solicitação

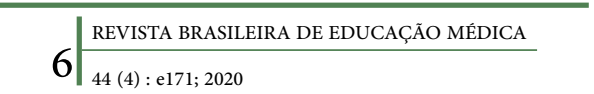


da família, mesmo que não haja prognóstico para o paciente. Há uma preocupação não só com a criança que está sendo atendida, mas com a família que está acompanhando tudo de perto. Entretanto, não é possível avaliar nos discursos se a postura dos instrutores seria diferente se a emergência acontecesse com um paciente não pediátrico.

Limitações do estudo

Uma análise mais aprofundada ou comparativa não pôde ser realizada, visto que, apesar da ampla busca sobre o tema de ressuscitação pediátrica na literatura, não foram encontrados dados semelhantes que pudessem dialogar com os encontrados na pesquisa. Observa-se que não há estudos que exploram a aplicabilidade do curso e a relação entre o ambiente simulado (curso) e o ambiente real (hospitalar), não sendo realizados estudos posteriores com o aluno e/ou o instrutor de PALS, a fim de acompanhar integralmente o percurso da aplicação da aprendizagem.

O estudo também foi realizado apenas com instrutores de PALS da Grande São Paulo, que normalmente estão vinculados a centros de treinamento de grandes hospitais particulares ou de ensino, o que limita a exploração da percepção dos instrutores nacionais e com maior vivência em hospitais públicos.

\section{CONCLUSÕES}

Segundo a percepção dos instrutores de PALS, cabe-lhes estabelecer a articulações entre o cenário simulado/ideal (curso) e o real (hospitalar) e entre o teórico/prático e o dia a dia, de modo a favorecer e fortalecer a aplicação das melhores práticas baseadas em evidência de ressuscitação pediátrica. Os instrutores percebem que são agentes de transformação e de mudança organizacional, assumindo a responsabilidade na aplicação e disseminação dessas melhores práticas dentro dos serviços assistenciais em que atuam, buscando continuamente melhorias, como a criação de protocolos, a aquisição de medicamentos e equipamentos e a elaboração de treinamentos. Os principais desafios para a implementação dessas melhores práticas foram a falta de treinamento das equipes, a ausência de recursos financeiros, o não apoio da gestão e as resistências. Os impactos percebidos na assistência após a implantação das melhorias no processo de ressuscitação pediátrica, segundo a óptica dos instrutores, foram a redução da mortalidade infantil e a melhor organização das equipes.

\section{AGRADECIMENTO}

A todos os instrutores do PALS que participaram do estudo e que aplicam na sua prática diária os ensinamentos ministrados.

\section{REFERÊNCIAS}

1. Carvalho P, Korb C, Dewes D, Braun Filho LR. Suporte Avançado de Vida em Pediatria: manual do profissional. São Paulo: Bandeirantes Soluções Gráficas; 2012.

2. Nadkarni MV, Larkin GL, Peberdy MA, Carey SM, Kaye W, Mancini $\mathrm{ME}$, et al. Documented rhythm and clinical outcome from in-hospital cardiac arrest among children and adults. JAMA. 2006;295(1):50-7.

3. Reis AG, Nadkarni V, Perondi MB, Grisi S, Berg RA. A prospective investigation into the epidemiology of in hospital pediatric cardiopulmonary resuscitation using the International Utstein Reporting Style. Pediatrics. 2002;109(2):200-9.

4. 4. Dane FC, Russell-Lindgren KS, Parish DC, Durham MD, Brown
TD. In hospital resuscitation: association between ACLS training and survival to discharge. Resuscitation. 2000;47(1):83-7.

5. Guimarães HP, Lopes RD, Timerman A, Flato UAP, Lane JC. A história da ressuscitação cardiopulmonar no Brasil. Rev Soc Bras Clín Méd. 2009;7(4):238-44.

6. Lima SG, Macedo LA, Vidal ML, Oliveira Sá MPB. Educação permanente em SBV e SAVC: Impacto no conhecimento dos profissionais de enfermagem. Arq Bras Cardiol. 2009;93(6):630-6.

7. Moretti MA. Eficácia do treinamento em suporte avançado de vida nos resultados das manobras de ressuscitação cardiopulmonar [tese]. São Paulo: Universidade de São Paulo; 2001.

8. Guimarães HP. Destaques da American Heart Association 2015: atualização das diretrizes de RCP e ACE. Dallas: American Heart Association; 2015.

9. Flato UAP, Guimarães HP. Educação baseada em simulação em medicina de urgência e emergência: a arte imita a vida. Rev Bras Clín Méd. 2011;9(5):360-4.

10. Guimarães HP, Da Costa MPF. Ressuscitação cardiopulmonar: uma abordagem multidisciplinar. Rio de Janeiro: Atheneu; 2007.

11. Joint Commission International. Padrões de Acreditação da Joint Commission International para Hospitais: incluindo padrões para hospitais - centros médicos acadêmicos. 6a ed. Oak Brook, IL: JCI; 2017.

12. Hospital Sírio-Libanês. Portal do IEP. Pediatric Advanced Life Support PALS [acesso em abr 2017]. Disponível em: https://iep.hospitalsiriolibanes. org.br/web/iep/-/pediatric-advanced-life-support-pals.

13. Minayo MCS. O desafio do conhecimento: pesquisa qualitativa em saúde. São Paulo: Hucitec; 2014. 407 p.

14. Gomes R. Pesquisa qualitativa em saúde. São Paulo: Instituto SírioLibanês de Ensino e Pesquisa; 2014. 45 p.

15. Minayo MCS, Cruz Neto O, Deslandes SF, Gomes R. Pesquisa social: teoria, método e criatividade. Petrópolis: Vozes; 2004.

16. Nairn S, Pinnock D. Pierre Bourdieu: expanding the scope of nursing research and practice. Nurs Philos. 2017;18(4):e12167. doi: 10.1111/ nup.12167.

17. Vilarinho PF. O campo da saúde suplementar no Brasil à luz da teoria do poder simbólico de Pierre Bourdieu. Cad EBAPE.BR. 2004;2(30);1-15 [acesso em 20 jan 2018]. Disponível em: http://www. scielo.br/pdf/cebape/v2n3/v2n3a08.

18. Montagner MA, Montagner MI. A teoria geral dos campos de Pierre Bourdieu: uma leitura. Rev Temp Actas Saúde Coletiva. 2010;5(2):255-73.

19. Araújo FMB, Alves EM, Cruz MP. Algumas reflexões em torno dos conceitos de campo e de habitus na obra de Pierre Bourdieu. Rev Perspect Ciênc Tecnol. 2009;1(1):31-40.

20. Setton MGJ. A teoria do habitus em Pierre Bourdieu: uma leitura contemporânea. Rev Bras Educ. 2002;20:60-70.

21. Cisse Ba SA, Rosalem V, Silva AV, Santos GC, Castro PA. Pierre Bourdieu e os estudos organizacionais: reflexividade crítica e comportamento analítica em gestores e colaboradores. Enciclopédia Biosfera. 2014;10(19):408-20 [acesso em out 2017]. Disponível em: www.conhecer.org.br/enciclop/ seminario/PIERRE.pdf.

22. Thiery-Cherques HR. Pierre Bourdieu: a teoria na prática. Rev Adm Publica (Rio de Janeiro). 2006;40(1):27-55.

23. Araújo CM, Oliveira MCSL. Contribuições de Bourdieu ao

\begin{tabular}{l|l}
7 & REVISTA BRASILEIRA DE EDUCAÇÃO MÉDICA \\
\hline $44(4):$ e e171; 2020
\end{tabular} 
tema do desenvolvimento adolescente em contexto institucional socioeducativo. Pesqui Prat Psicossociais. 2014;8(2):216-25.

24. Alves ER. Pierre Bourdieu: a distinção de um legado de práticas e valores culturais. Soc Estado (Brasília). 2008;23(1):179-84.

25. Conselho Federal de Enfermagem. Resolução no 311, de 17 de fevereiro de 2007. Aprova a Reformulação do Código de Ética dos Profissionais de Enfermagem [acesso em 20 jan 2018]. Disponível em: http://www.cofen.gov.br/resoluo-cofen-3112007_4345.html.

26. Conselho Federal de Medicina. Resolução $n^{\circ} 1.931$, de 14 de setembro de 2009. D.O.U., Brasília, DF; 24 set 2009; Seção I, p. 90. Retificação publicada no Diário Oficial da União, Brasília (DF); 13 out 2009; Seção I, p. 173. Aprova o Código de Ética Médica [acesso em 20 jan 2018]. Disponível em: http://www.portalmedico.org.br/resolucoes/ CFM/2009/1931_2009.htm.

27. Conselho Federal de Medicina. Resolução CFM no 2.110, de 19 de novembro de 2014. Publicada do Diário Oficial da União, Brasília, DF, 19 nov 2014; Seção I, p. 199. Modificada pela Resolução CFM $\mathrm{n}^{\circ}$ 2.132/2015. Modificada pela Resolução CFM no 2.139/2016. Dispõe sobre a normatização do funcionamento dos Serviços Pré-
Hospitalares Móveis de Urgência e Emergência, em todo o território nacional [acesso em 20 jan 2018]. Disponível em: http://www. portalmedico.org.br/resolucoes/CFM/ 2014/2110_2014.pdf.

28. Zimermmann F. Gestão da Estratégia com BSC - fundamentos. Brasília: Escola Nacional de Administração Pública; 2016.

\section{CONTRIBUIÇÃO DOS AUTORES}

Lisiane Valdez Gaspary elaborou o artigo. Edison Ferreira de Paiva revisou o texto.

\section{CONFLITO DE INTERESSES}

Os autores declaram não haver conflitos de interesse.

\section{ENDEREÇO PARA CORRESPONDÊNCIA}

Lisiane Valdez Gaspary. Estrada de São Francisco, 2701, ap. 94 IV, Taboão da Serra, SP, Brasil. CEP: 06764-290.

E-mail: lisivg@hotmail.com 